\title{
Sustained Increase in Narp Protein Expression Following Repeated Electroconvulsive Seizure
}

\author{
Irving M. Reti, M.B.B.S., and Jay M. Baraban, M.D., Ph.D.
}

The delayed response to many psychiatric treatment regimens has focused attention on identifying enduring changes in gene expression following repeated stimulation that may contribute to these responses. Recent studies have identified Narp protein as a neuronal immediate early gene product that remains elevated in the hippocampus nearly 24 hours after a single episode of electroconvulsive seizure (ECS). To examine how Narp expression responds to repeated stimulation, we have examined the effect of repeated ECS on Narp expression in the hippocampus. We report that Narp protein levels remain elevated, about sixfold higher than basal levels, at 48 hours after the last of a series of five or six ECS given every other day. As Narp protein appears to play a key role in regulating AMPA receptor clustering at synaptic sites, sustained increases in Narp may contribute to changes in excitatory synaptic transmission induced by chronic neuronal stimulation. [Neuropsychopharmacology 23:439-443, 2000] (C) 2000 American College of Neuropsychopharmacology. Published by Elsevier Science Inc.
KEY WORDS: Pentraxin; ECT; AMPA receptors; Immediate early gene; Hippocampus

A central focus of current research in psychopharmacology is to understand the molecular alterations that underlie the long-term effects of psychiatric treatments. Accordingly, there has been intense interest in identifying slowly developing or prolonged changes in gene expression that are induced by repeated administration of psychotropic drugs or ECT (Hyman and Nestler 1996). Although a single ECS episode triggers a rapid induction of multiple immediate early genes (IEG), in most cases examined to date, the expression of these IEGs follows a rapid and transient time course

From the Departments of Neuroscience (JMB) and Psychiatry and Behavioral Sciences (JMB, IMR), The Johns Hopkins School of Medicine, Baltimore, MD.

Address correspondence to: Jay M. Baraban, The Johns Hopkins University, School of Medicine, 725 N. Wolfe St., Baltimore, MD 21205.

Received February 8, 2000; revised March 22, 2000; accepted March 24, 2000 making it unclear whether they contribute to long-term changes elicited by these treatments. Two notable exceptions to this pattern are $\Delta$ Fos B (Chen et al. 1997; Hiroi et al. 1998) and BDNF (Duman and Vaidya 1998; Nibuya et al. 1995; Zetterstrom et al. 1998), which display enduring changes in expression following chronic treatment regimens.

In recent studies, Narp has been identified as an IEG product that also displays an atypical, sluggish time course of expression, as it takes 4-8 hours to reach peak levels and remains elevated for nearly 24 hours after a single ECS (O'Brien et al. 1999; Tsui et al. 1996). Functional analysis of Narp has provided compelling evidence that it regulates clustering of AMPA receptors at synaptic sites and may therefore contribute to alterations in excitatory synaptic transmission induced by neuronal stimulation. Both the distinctive time course displayed by Narp and its link to synaptic plasticity make it an attractive candidate gene that might mediate long-term effects of psychiatric treatments. Accordingly, as an initial step in examining how its expression is affected by repeated stimulation, we have monitored the expression of Narp protein following repeated ECS. 


\section{MATERIALS AND METHODS}

Maximal ECS was administered to male Sprague-Dawley rats (175-200 g) (Harlan, Indianapolis, IN) as described in Cole et al. (1990). Sham treated rats were handled identically to those receiving ECS except for administration of the electrical current. For repeated ECS, stimulation was administered at 48 hour intervals.

To monitor Narp protein levels at various times after single or repeated ECS, animals were killed by decapitation with a small animal guillotine. Hippocampal tissues were dissected and then placed in Laemmli sample buffer (BioRad, Hercules, CA) with additional SDS (3\% final concentration). Samples were homogenized, then heated for 1 minute at $65^{\circ} \mathrm{C}$. Except where explicitly stated, higher temperatures and the addition of $\beta$-mercaptoethanol were not used as both disrupted the Narp multimeric complex. Protein concentrations were determined by Amido Black assay (Sheffield et al. 1987) and aliquots of each sample ( $25 \mu \mathrm{g}$ of protein) were separated by $6 \%$ SDS-PAGE. After electrophoretic transfer to nitrocellulose membranes overnight, blots were probed with Narp antibodies (provided by P. Worley) against either the C-terminal peptide or a full-length
Narp/GST fusion protein (Tsui et al. 1996). Bands were visualized with ECL. A quantitative estimate of Narp protein levels was obtained by measuring optical density from film using Scion Image (Scion Corporation, Frederick, MD).

To monitor changes in Narp mRNA, we performed in situ hybridization studies (ISH). Hemibrains obtained from control and treated animals were embedded together using the procedure described in Cole et al. (1990). Sense and anti-sense Narp riboprobes were prepared from 5'-end (464 bp) and 3'-end (151 bp) linearized segments, respectively, of the full-length Narp cDNA subcloned in pBluescript. Riboprobe synthesis and hybridization were performed as described in $\mathrm{Ma}$ et al. (1999).

\section{RESULTS}

Previous biochemical characterization of Narp and other pentraxin family members indicates that these proteins form pentameric complexes which assemble into larger aggregates in vivo (Marnell et al. 1995; Tsui et al. 1996). Consistent with those reports, we found that



Figure 1. Induction of Narp protein in hippocampus by a single ECS. In lanes 1 and 2, a Western blot, probed with the fulllength Narp/GST fusion antibody at dilution of 1:1000, shows expression of Narp protein in hippocampal extracts harvested 8 hours after a sham (control) or single ECS (1X $+8 \mathrm{hr})$. Narp migrates as a large multimeric complex and is strongly induced by ECS. A band at $150 \mathrm{kD}$ is not induced by ECS. Lane 3 shows the blot in lane 2 after it has been stripped and probed with a distinct Narp antibody prepared against the C-terminal. Both the C-terminal and full-length Narp antibodies recognize high molecular weight complexes that co-migrate identically. However, they detect distinct faster migrating bands. (Pre-incubation with a C-terminal peptide at $10 \mu \mathrm{g} / \mathrm{ml}$ blocks all bands detected by the C-terminal antibody.) Lane 4 shows a Western blot of hippocampal samples harvested 8 hours after ECS, and then incubated with $5 \% \beta$-mercaptoethanol at $100 \mathrm{C}$ for 3 minutes. The blot, probed with the full-length Narp antibody, reveals that this treatment causes the disappearance of the slowly migrating Narp complex, along with the appearance of a $46 \mathrm{kD}$ band, the expected size of the Narp monomer. In contrast, the $150 \mathrm{kD}$ band is unaffected by this treatment. Similar results were obtained with the C-terminal antibody, i.e., the slowly migrating complex vanishes, a $46 \mathrm{kD}$ band appears and the 97 and $220 \mathrm{kD}$ bands are unaffected. 
both Narp antibodies detected a band that migrates very slowly on SDS-PAGE, well behind the $220 \mathrm{kD}$ marker (Figure 1). As expected for the Narp protein band, the intensity of this band is increased markedly by ECS in the hippocampus. In addition to this inducible Narp band, these antibodies also recognized faster migrating bands in the $97-220 \mathrm{kD}$ range.

Although it is conceivable that these faster migrating bands represent Narp-containing complexes, none of these bands were recognized by both antibodies suggesting that they reflect non-specific cross-reactvity associated with each of the antisera. To explore this issue further, we also examined the sensitivity of the bands detected by Narp antibodies to incubation with $\beta$-mercaptoethanol, as O'Brien et al. (1999) demonstrated that the Narp multimeric complex dissociates when incubated with this sulfhydryl reducing agent. As expected, we found that the slowest migrating band was abolished by this treatment which also led to the appearance of a $46 \mathrm{kD}$ band, the expected size of the Narp monomer (Figure 1, lane 4). In contrast, the faster migrating bands, detected by either of the Narp antibodies, were unaffected by this treatment. These findings provide further confirmation that the slowest migrating complex, that is strongly induced by seizure activity, is a Narp multimeric complex, and suggest that the faster migrating complexes may represent cross-reacting bands.

To assess the effect of repeated ECS on Narp protein levels, we administered ECS every other day over the course of 10 days. We found a significant increase in Narp protein levels in hippocampal extracts harvested 48 hours after five or six ECS, with protein levels returning to baseline levels after seven days (Figure 2). Furthermore, determining the sample dilution needed to reduce the intensity of the Narp protein band to control levels, indicated that there is a six-fold increase in Narp protein levels in extracts harvested 48 hours after the fifth or sixth seizure episode compared with control extracts.

To determine if the observed increase in Narp protein levels reflects a sustained increase in Narp mRNA levels, we also conducted ISH studies following repeated ECS (Figure 3). These studies demonstrated that the robust rise in Narp mRNA detected at 2 hours after a single ECS is still induced after the sixth ECS, consistent with the increase in Narp protein levels observed after the last ECS. However, in contrast to Narp protein, mRNA levels were not elevated at 48 hours after a series of ECS. Thus, the increase in protein levels seen at 48 hours after five or six ECS does not reflect a sustained increase in Narp mRNA levels.
A control $1 \mathrm{X}+8 \mathrm{hr} 1 \mathrm{X}+24 \mathrm{hr} 1 \mathrm{X}+48 \mathrm{hr} 5 \mathrm{X}+48 \mathrm{hr} 6 \mathrm{X}+8 \mathrm{hr} 6 \mathrm{X}+24 \mathrm{hr} 6 \mathrm{X}+48 \mathrm{hr} 6 \mathrm{X}+7 \mathrm{~d}$

B

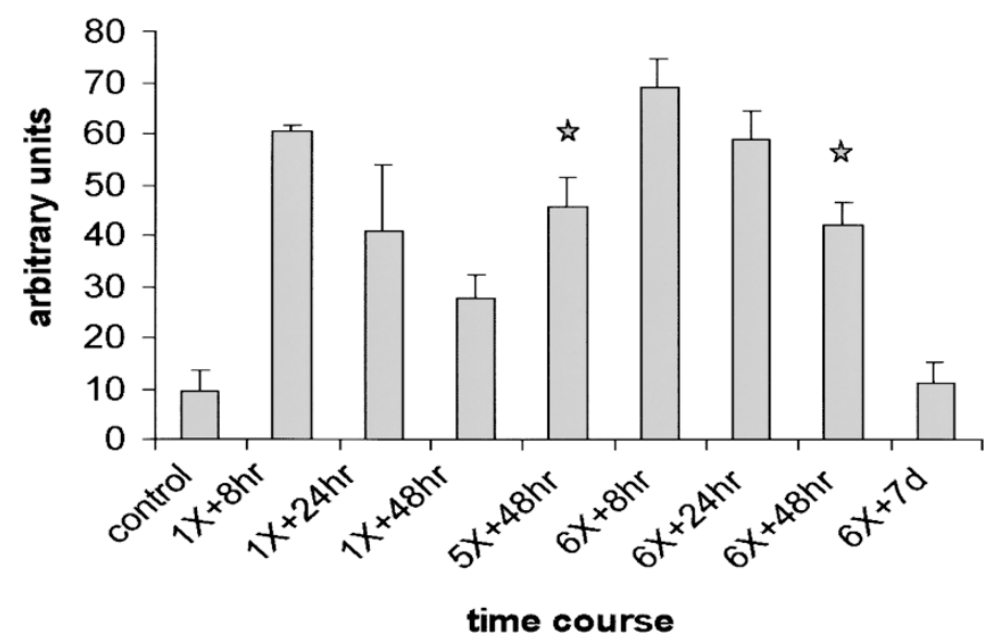

Figure 2. Repeated ECS induces a sustained increase in hippocampal Narp protein expression. Rats treated with acute ECS were killed 8, 24, or 48 hours after ECS. Animals treated chronically received ECS on alternate days, and were killed $48 \mathrm{hrs}$ after the fifth treatment or $8,24,48$ hours, or 7 days after the sixth treatment. Control animals received six sham treatments. Three sets of nine animals were used for these studies. Extracts harvested from each set of animals were processed in parallel and analysed on the same blot as shown in panel A. The similar results obtained from all three sets of animals are summarized in panel B. ANOVA comparing Narp protein levels in control and ECS groups revealed a significant difference: $\mathrm{F}(8,18)=11.68, p<$ .001 . Post-hoc analysis (LSD t-test) indicated that $5 \mathrm{X}+48 \mathrm{hr}$ and $6 \mathrm{X}+48 \mathrm{hr}$ differed significantly from control $\left({ }^{*} p<.005\right)$, but that there was no significant difference between $1 \mathrm{X}+48$ and control. Also, by Student's t-test, the combined values obtained for time points $5 X+48$ and $6 X+48$ differ significantly from those obtained at $1 \mathrm{X}+48(p<$ .05). Error bars represent the standard errors of the mean. 

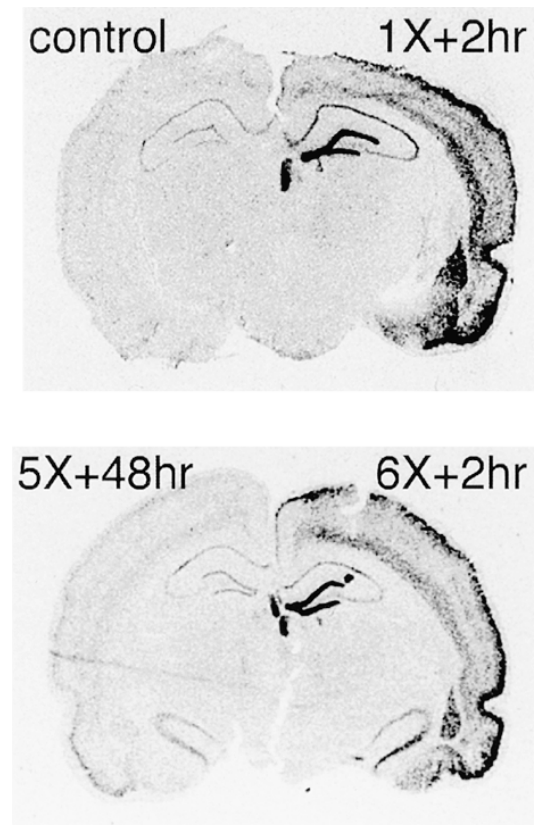

Figure 3. ISH analysis of Narp mRNA levels following ECS. Brains from rats that underwent ECS were harvested 2 hours after a single ECS episode (1X $+2 \mathrm{hr}), 48$ hours after the fifth episode $(5 \mathrm{X}+48 \mathrm{hr})$, or 2 hours after the sixth episode $(6 \mathrm{X}+2 \mathrm{hr})$. Control animals received six sham treatments. Control and experimental brains were bisected along the mid-sagittal plane, aligned, and then frozen in the same block. Sections hybridized with sense riboprobe were blank. Narp mRNA returns to basal levels by 48 hours after five ECS. Similar results were obtained in three sets of rats. The intensely stained structure located medial to the dentate gyrus is the habenula. Narp mRNA expression in the habenula is strong in both control and treated animals. (The habenula of the control hemisection was lost when bisecting the brain along the mid-sagittal plane.) High levels of expression of other IEG's in the habenula, such as c-fos and zif268, have been noted previously (Da Costa et al. 1997).

\section{DISCUSSION}

The major finding of this study is that Narp expression remains elevated for at least 48 hours following repeated ECS. Thus, these data indicate that a series of ECS spaced at 48 hour intervals, similar to the paradigm used clinically, generates a sustained increase in Narp protein levels. The increased level of Narp protein expression detected 48 hours after either 5 or 6 seizure episodes occurs in the absence of elevations in Narp mRNA at those times. These findings suggest that as found for $\Delta$ Fos-B (Chen et al. 1997; Kelz et al. 1999), the relatively long half-life of Narp protein may lead to its accumulation after repeated stimulation. Since Narp mRNA is induced in striatum by manipulations of the dopamine system (Berke et al. 1998), it will be interesting to assess whether repeated administration of drugs affecting dopaminergic tone also lead to long-lasting elevations in Narp protein levels.

Although in vitro studies have demonstrated that Narp plays a key role in clustering of AMPA receptors, it is still unclear how Narp expression affects excitatory synaptic transmission. Nevertheless, it is conceivable that Narp plays a role in the alterations in AMPA receptor function critically involved in synaptic plasticity. Thus, the sustained induction of Narp could mediate the alterations in synaptic responsiveness of dentate granule cells to the perforant path input induced by repeated ECS (Stewart and Reid 1993). In this context, it is also interesting that repeated ECS leads to a marked increase in the expression of GluR1 mRNA in hippocampal neurons (Naylor et al. 1996). Thus, increased Narp expression may be needed to localize newly synthesized AMPA receptors at synaptic sites.

In summary, we have found that Narp protein displays a sustained increase in expression in the hippocampus following a series of ECS. These findings suggest a potential mechanism through which repeated electrophysiological or pharmacological stimuli can elicit prolonged changes in excitatory synaptic transmission. Since changes in AMPA receptor sensitivity have been implicated in mediating behavioral alterations elicited by chronic pharmacological stimulation (Carlezon et al. 1999; Wolf 1998), it will be important in future studies to assess whether Narp is involved in mediating the adaptive changes triggered by these treatments.

\section{ACKNOWLEDGMENTS}

We wish to thank Paul Worley and Radhika Reddy for the Narp antibodies and Narp plasmid, and Xin-Ming Ma for advice on ISH.

\section{REFERENCES}

Berke JD, Paletzki RF, Aronson GJ, Hyman SE, Gerfen CR (1998): A complex program of striatal gene expression induced by dopaminergic stimulation. J Neurosci 18(14):5301-5310

Carlezon WA Jr, Rasmussen K, Nestler EJ (1999): AMPA antagonist LY293558 blocks the development, without blocking the expression, of behavioral sensitization to morphine. Synapse 15;31(4):256-262

Chen J, Kelz MB, Hope BT, Nakabeppu Y, Nestler EJ (1997): Chronic Fos-related antigens: Stable variants of delta FosB induced in brain by chronic treatments. J Neurosci 17(13):4933-4941

Cole AJ, Abu-Shakra S, Saffen DW, Baraban JM, Worley PF (1990): Rapid rise in transcription factor mRNAs in rat brain after electroshock-induced seizures. J Neurochem 55(6):1920-1927

Da Costa AP, Broad KD, Kendrick KM (1997): Olfactory 
memory and maternal behavior-induced changes in c-fos and zif268 mRNA expression in the sheep brain. Brain Res Mol Brain Res 46(1-2);63-67

Duman RS, Vaidya VA (1998): Molecular and cellular actions of chronic electroconvulsive seizures. J Ect 14(3):181-193

Hiroi N, Marek GJ, Brown JR, Ye H, Saudou F, Vaidya VA, Duman RS, Greenberg ME, Nestler EJ (1998): Essential role of the fosB gene in molecular, cellular, and behavioral actions of chronic electroconvulsive seizures. J Neurosci 18(17):6952-6962

Hyman SE, Nestler EJ (1996): Initiation and adaptation: A paradigm for understanding psychotropic drug action. Am J Psychiatry 153:151-162

Kelz MB, Chen J, Carlezon WA Jr, Whisler K, Gilden L, Beckmann AM, Steffen C, Zhang YJ, Marotti L, Self DW, Tkatch T, Baranauskas G, Surmeier DJ, Neve RL, Duman RS, Picciotto MR, Nestler EJ (1999): Expression of the transcription factor deltaFosB in the brain controls sensitivity to cocaine. Nature 401(6750):272-276

Ma XM, Lightman SL, Aguilera G (1999): Vasopressin and corticotropin-releasing hormone gene responses to novel stress in rats adapted to repeated restraint. Endocrinology 140(8):3623-3632

Marnell L, Mold C, Volzer MA, Burlingame RW, Du Clos TW (1995): Expression and radiolabeling of human C-reactive protein in baculovirus-infected cell lines and Trichoplusiani larvae. Protein Expr Purif 6(4):439-446

Naylor P, Stewart CA, Wright SR, Pearson RC, Reid IC
(1996): Repeated ECS induces GluR1 mRNA but not NMDAR1A-G mRNA in the rat hippocampus. Brain Res Mol Brain Res 35(1-2):349-353

Nibuya M, Morinobu S, Duman RS (1995): Regulation of BDNF and trkB mRNA in rat brain by chronic electroconvulsive seizure and antidepressant drug treatments. J Neurosci 15(11):7539-7547

O'Brien RJ, Xu D, Petralia RS, Steward O, Huganir RL, Worley P (1999): Synaptic clustering of AMPA receptors by the extracellular immediate-early gene product Narp. Neuron 23:309-323

Sheffield JB, Graff D, Li HP (1987): A solid-phase method for the quantitation of protein in the presence of sodium dodecyl sulfate and other interfering substances. Anal Biochem 166(1):49-54

Stewart C, Reid I (1993): Electroconvulsive stimulation and synaptic plasticity in the rat. Brain Res 620(1):139-141

Tsui CC, Copeland NG, Gilbert DJ, Jenkins NA, Barnes C, Worley P (1996): Narp, a novel member of the pentraxin family, promotes neurite outgrowth and is dynamically regulated by neuronal activity. J Neurosci 16 (8):24632478

Wolf ME (1998): The role of excitatory amino acids in behavioral sensitization to psychomotor stimulants. Prog Neurobiol 54(6):679-720

Zetterstrom TS, Pei Q, Grahame-Smith DG (1998): Repeated electroconvulsive shock extends the duration of enhanced gene expression for BDNF in rat brain compared with a single administration. Mol Brain Res 57(1):106-110 